\title{
The role of product reviews on mobile devices for in-store purchases: consumers' usage intentions, costs and store preferences
}

\author{
Tobias Kowatsch* \\ Institute of Technology Management, \\ University of St. Gallen (ITEM-HSG), \\ Dufourstrasse 40a, 9000 St. Gallen, Switzerland \\ Fax: +41-71-224-7301 \\ E-mail: tobias.kowatsch@unisg.ch \\ *Corresponding author
}

\section{Wolfgang Maass}

\author{
Institute of Technology Management, \\ University of St. Gallen (ITEM-HSG), \\ Dufourstrasse 40a, 9000 St. Gallen, Switzerland \\ and \\ Research Center for Intelligent Media, \\ Hochschule Furtwangen University, \\ Robert-Gerwig-Platz 1, 78120, Furtwangen, Germany \\ Fax: +41-71-224-7301 \\ E-mail: wolfgang.maass@unisg.ch
}

\section{Elgar Fleisch}

Institute of Technology Management, University of St. Gallen (ITEM-HSG), Dufourstrasse 40a, 9000 St. Gallen, Switzerland and Swiss Federal Institute of Technology (ETH), Scheuchzerstrasse 7, 8092 Zurich, Switzerland Fax: +41-71-224-7301

E-mail: elgar.fleisch@unisg.ch

\begin{abstract}
Product reviews help consumers in purchase decisions. In contrast to reviews obtained from websites on the desktop, it is open if they are adopted for in-store purchases on mobile devices. Further, it is open to which degree free product reviews provided by users or paid product reviews provided by experts are adopted and influence consumers' preferences for stores that offer access to them. To address these questions, a theoretical model based on innovation diffusion theory, technology acceptance model and theory of planned behaviour is developed and empirically tested with 116 subjects. Results indicate that consumers intend to use product reviews on mobile devices for in-store purchases. Moreover, they are willing to pay almost $5 \%$ of the product's price for a review. Based on these findings, new business models
\end{abstract}


for providers of product reviews and store managers are feasible, which extend physical products with value-added online services.

Keywords: consumer behaviour; in-store store shopping; product reviews; mobile device; costs; empirical study; store preferences; usage intentions; internet marketing; mobile marketing.

Reference to this paper should be made as follows: Kowatsch, T., Maass, W. and Fleisch, E. (2011) 'The role of product reviews on mobile devices for in-store purchases: consumers' usage intentions, costs and store preferences', Int. J. Internet Marketing and Advertising, Vol. 6, No. 3, pp.226-243.

Biographical notes: Tobias Kowatsch is a Research Associate and a $\mathrm{PhD}$ candidate at ITEM-HSG. His research interests in the management of information systems are the adoption and diffusion of innovations, consumer behaviour, mobile business, smart products, internet of things and recommendation agents. He studied Computer Science in Media at Hochschule Furtwangen University (HFU) in Germany and wrote his Diploma thesis about semantic web applications in 2005. After studying in Scotland and doing social volunteering in South Africa, he attended the Master's programme in Computer Science in Media at HFU in 2006 and passed with distinction. Then, he did empirical research on the user acceptance of mobile information systems at the Research Center for Intelligent Media at HFU.

Wolfgang Maass leads the division Smart Products at ITEM-HSG. He is a University Lecturer at the University of St. Gallen and a Professor of Media and Computer Science at Hochschule Furtwangen University where he is also the Head of the Research Center for Intelligent Media (RCIM). His research interests in information management and information systems include ambient intelligence with a focus on smart products, internet of things, electronic knowledge markets and paid content. He is a member of the editorial board of Electronic Markets and a reviewer for the European Journal of Information Systems, The International Journal on Media Management, and the Journal of Theoretical and Applied Electronic Commerce Research. He received his $\mathrm{PhD}$ from the University of Saarbrücken in Germany. In the end of 2007, he was awarded with a habilitation by the Department of Management at the University of St. Gallen.

Elgar Fleisch is a Professor of Information and Technology Management at ETH Zurich and the University of St. Gallen. His research focuses on the economic impacts and infrastructures of ubiquitous computing. In the Auto-ID Lab, he and his team develop, in concert with a global network of universities, an infrastructure for the internet of things. In the Bits-to-Energy Lab, which he co-chairs with Prof. Mattern of ETH Zurich, he investigates and designs technologies and applications to save electrical power, and in the Insurance Lab, he, together with Prof. Ackermann of HSG, drives forward technology-based innovation in the insurance industry. All research projects are joint efforts of industry and academia; their results have been published in more than 200 scientific journals and books. He is a Co-founder of several university spin-offs and he serves as a member of multiple management boards and academic steering committees. 


\section{Introduction}

Word-of-mouth has long been recognised as a major driver of product sales as quality uncertainty and high search costs for identifying relevant product information may prevent consumers from making purchases (Chen et al., 2004). Particularly in online purchase situations, almost the half of the 5,500 participants of a BizRate survey said that they have consulted opinion sites before they made a purchase (Piller, 1999). In addition, the internet has not only significantly reduced the consumers' information-retrieval cost (Moon, 2004) but also the reviewers' information-delivery cost (Chen and Xie, 2005). Thus, a lot of free digital product reviews are available on Amazon.com, DooYoo.co.uk, Ciao.de, eOpinions.com and Ask.com among other web 2.0 review platforms. In addition, several expert magazines provide digital product reviews for free, e.g., PC Praxis, Car and Driver or Runner's World. But there are also paid digital product reviews available from experts. For instance, consumer and test magazines such as Consumer Reports, AudioVision, or Stiftung Warentest regularly publish paid reviews on their websites.

As digital product reviews are adopted through websites at home, they may also be used on mobile devices in in-store purchase situations. Correspondingly, mobile applications are being developed for consumers to communicate with products (Maass and Varshney, 2008). Mobile shopping assistants such as MASSI (Metro AG), the Tip'n Tell client (Kowatsch and Maass, 2010), the Mobile Prosumer (Resatsch et al., 2008), or APriori (von Reischach and Michahelles, 2008) allow to request product information directly at the point of sale. For example, an electronic consumer good is identified by a mobile barcode or RFID reader device and then provides its information, which is obtained from a web service, such as the recommended sales price, its producer or other products that fit with it (Maass et al., 2008). In that case, physical products can be enriched with a new digital content service in the form of product reviews. This would not only change the way retail stores are perceived by consumers, e.g., they might request reviews directly at the point of sale instead at home, but this would also have managerial implications for retailers and providers of reviews. In this sense, several research questions are relevant such as: are digital product reviews in retail stores adopted at all? How much (if at all) should the provider charge for product reviews? How should reviews be designed? Which technology is accepted and usable for consumers? Or how should interfaces for mobile devices be designed in order to retrieve product information fast and efficient.

In this paper, we focus on the first two questions stated above, because costs of digital product reviews are a main concern from the consumer's perspective and may influence their adoption predominantly. Up until now and to the best of our knowledge, it is open

1 whether digital product reviews are adopted at all by using mobile devices in retail stores

2 how costs influence their adoption when provided for free by users or for a fee by experts

3 how costs influence the store preference of consumers

4 whether the review's adoption rate positively influences consumers' preferences of stores that have access to digital product reviews. 
This paper provides first answers to these questions by conducting an empirical study. It is organised as follows. In the next section, related work is described. Then, our research model and hypotheses are developed, followed by the methodology section that explains the design of the study, instrument selection and data analysis. After this, results are presented and discussed with respect to managerial implications and design guidelines for further lab experiments and review information systems. Finally, we conclude our work and provide an outlook on future research.

\section{Related work}

According to Konana and Ray (2007), physical products increasingly incorporate information technology that facilitates the differentiation of products in competitive markets. For instance, RFID-based electronic product codes (EPC) allow the retrieval of associated product information that can be used for product or service differentiation. Products that actively use information services for adaptations to situations, users and other products are denoted as smart products (Maass and Varshney, 2008). They are claimed to be situated, personalised, adaptive, pro-active, business-aware and network-capable (Maass et al., 2008). The potential of new business models and services for smart products (e.g., products may be able to sell themselves) is suggested to be very high (Konana and Ray, 2007). In particular, product review services provided by third parties can be implemented by attaching the corresponding information to the smart product.

On the other side, mobile commerce is starting to become a promising and lucrative growth market (Kim et al., 2007). It allows electronic commerce activities on mobile devices such as on mobile phones or PDAs (Lee and Benbasat, 2003). Thus, product recommendation services will be not only available within online shopping situations at home where they have recently gained major interest in the information systems research community (Bo and Benbasat, 2007) but also in retail stores on mobile devices (Kowatsch and Maass, 2010). Bo and Benbasat (2007, p.137) define integrated sets of recommendation services as "software agents that elicit the interest or preferences of individual users for products either explicitly or implicitly, and make recommendations accordingly". Several studies showed that recommendation agents provide value-added services that help to reduce customer's information overload in shopping situations and reduce search complexity (Häubl and Trifts, 2000) and trust in decisions (Komiak and Benbasat, 2006). According to this paper, those agents may also recommend product reviews with all the benefits described above.

Already ten years ago, the diffusion of product reviews was remarkable as the opinion collector BizRate.com, which compiles consumer ratings of e-commerce web merchants, had nearly 2.1 million users (Piller, 1999). Jiang and Wang (2008) discuss economic impacts of reviews depending on their informativeness, the number of product attributes and competitive markets. For digital cameras and multivitamin products provided by Amazon, they find that a monopolist benefits from positive product ratings whereas companies in competitive markets can be hurt by it. Li and Hitt (2008) suggest to change marketing strategies to get positive reviews based on empirical findings of online reviews at Amazon as they may be subject to self-selection biases influencing consumer purchase behaviour and consumer surplus. For the same review platform, the impact of user reviews on sales was investigated (Chen et al., 2004). The authors found that the number 
of consumer reviews is positively related to sales, in particular when products (here books) are less popular. Another important factor influencing sales is the fit of reviews from peers and experts. In this regard, consumers are likely to adopt a product if the corresponding reviews from both peers and experts reflect a high level of consensus as found by Wang (2008). Furthermore, perceived helpfulness of customer reviews was studied by Mudambi and Schuff (2010) for search and experience goods. The authors found that review extremity, review depth and product type affect helpfulness. A DoubleClick study in 2004 revealed that for some product categories such as consumer electronics online review sites have a greater influence on purchase decisions than any other medium (DoubleClick, 2004).

Corresponding to the current work, first prototypes of mobile applications are being developed that facilitate the use of product reviews in bricks-and-mortar stores. For example, APriori allows to access and to generate product reviews on mobile phones (von Reischach and Michahelles, 2008). Other prototypes provide access to diet and nutrition information of groceries (Maes and Mistry, 2009).

\section{Research model and hypotheses}

Digital product reviews are digital contents (Shapiro and Varian, 1999). They can be classified into free contents or paid contents (Stahl and Maass, 2006). In the following, stores, in which consumers have access to digital product reviews, are denoted as review-enabled stores. According to the research questions stated in the introduction, we study the use of free and paid digital product reviews that are obtained by mobile devices at the point of sale in general and under the conditions

1 that a fee has to be paid for them

2 that they are provided for free.

In addition, the relationship between the presence of fees, the adoption of reviews and the intention to prefer review-enabled stores is evaluated. An overview of our research model is depicted in Figure 1.

Figure 1 Research model

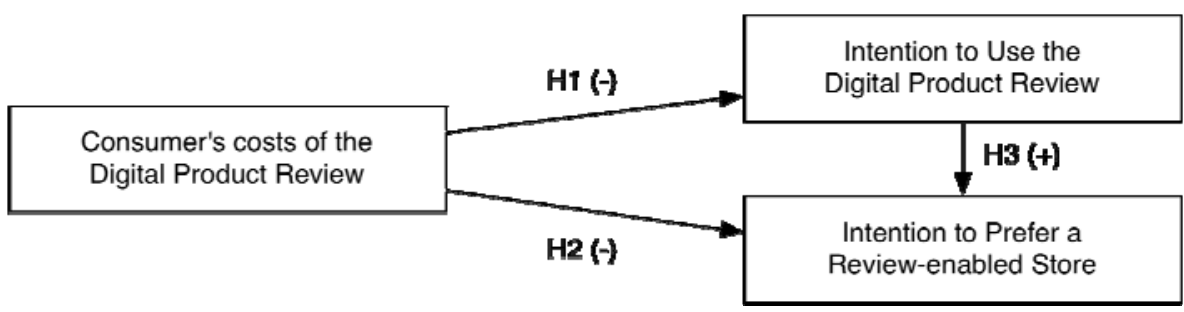

We study the adoption of digital product reviews by using models of diffusion of innovation and technology acceptance research because reviews represent an innovation that the consumer can adopt for application in purchase decision situations. Two streams of research can be identified in the adoption of innovations. First, diffusion of innovation research investigates perceived characteristics of innovations such as relative advantage, 
compatibility and complexity. These characteristics are identified as determinants for adopting or rejecting new innovations (Rogers, 2003). The second line of research studies intention-based models to understand the adoption of innovations. Accordingly, theory of reasoned action (TRA, Ajzen and Fishbein, 1980) and theory of planned behaviour (TPB, Ajzen, 1991) are taken from the field of social psychology to identify attitudes, social influences and facilitating conditions that predict the intention of usage. Thus, the intention to use product reviews predicts their adoption. For instance, TAM is based upon this line of research (Davis, 1989). In addition, several studies successfully integrate both research domains (Moore and Benbasat, 1991; Venkatesh et al., 2003a). Consistent with the latter, this article takes both perspectives into account, too.

According to Venkatesh et al. (2003b, p.453), facilitating conditions include aspects of the technological and/or organisational environment that are designed to remove barriers to use. Regarding the current work, these barriers are costs the consumer has to pay before using a review. We consider costs by means of a review's price tag. Consumers may pay for a digital product review provided by an expert if they expect better purchase decisions and thus, reduce negative outcomes related to the product after purchase (Bettman et al., 1998). In that case, consumers may adopt paid content if they expect that the review's information is worth it (Raban, 2007; Stahl and Maass, 2006). Thus, the consumer needs to make a trade-off between costs for the review in advance and the expected outcome of the product purchase. It is still open for which kinds of products this trade-off leads to the adoption of paid digital product reviews, but as products in retail stores represent rather low or medium complex products (e.g., groceries or consumer electronics) compared to high-complex products such as cars, houses, or insurance bundles, the risk to lose money when not using a digital product review by an expert is lower. And with the availability of user-generated reviews that can be obtained for free (Li and Hitt, 2008; Chen et al., 2004), the perceived value of paid reviews may decrease as well and consumers may intend to use free product reviews rather than reviews they have to pay for. With regard to these aspects, we propose the following hypothesis.

H1 The intention to use a digital product review is lower if the consumer has to pay for it even though an expert provides it.

As costs of a review may prevent its adoption, also retail stores that provide them may be less preferred. Thus, we suggest that the consumers' costs of a review negatively influence the intention to prefer a review-enabled store. This construct is related to the intention to return measure (Kamis et al., 2008) as it is an indicator of repeated store visits. It is therefore relevant for retailers and their sales when considering their customers' loyalty behaviour (Kabadayi and Gupta, 2005; La et al., 2005; van Riel et al., 2004).

H2 The intention to prefer a review-enabled retail store is lower if the consumer has to pay for the digital product review even though an expert provides it.

And finally, with regard to TRA/TPB, the usage of electronic reviews in retail stores is predicted by consumers' behavioural intentions. Correspondingly, the action can only be performed in review-enabled stores as they allow the behaviour in question, the usage of the review. In line with Bitner (1992, p.67), we assume review-enabled retail stores to be more in the role of a facilitator that supports the ability of consumers to carry out their respective activities, i.e., to use a digital product review. Thus, store preference reflects 
rather a positive inclination towards a store than a primary preference factor. As a result, we hypothesise the last relationship as follows.

H3 The intention to use a digital product review has a positive relationship with the intention to prefer a store that offers them.

Although there exist many other factors that predict behavioural intentions with regard to TAM (e.g., perceived usefulness) or TRA/TPB (e.g., behavioural and normative believes, attitudes toward the behaviour and subjective norm) and which would lead to additional hypotheses, we focus on the costs of digital product reviews in the sense of perceived behavioural control in the current work. The rationale behind this approach is that we neither test a concrete instance of digital product reviews nor a mobile application that provides them and which might then allow us to test their usefulness among other factors. We only test the adoption of digital product reviews for in-store shopping situations from a holistic perspective. This approach allows us to report early findings on adoption behaviour that will then guide the design of mobile applications and corresponding business models for which the costs are the most important factor. From a design science perspective (Hevner et al., 2004), we therefore first identify business needs with the current work, i.e., we focus on the question whether digital product reviews are adopted in retail stores and whether consumers would even pay for them, before a concrete instance is build and evaluated with regard to other factors as discussed above.

\section{Methodology}

\subsection{Study design}

In order to test the research model, we employed a $2 \times 3$ factorial study design as shown in Table 1. The treatments were the type of the product review (free reviews vs. paid reviews) and the product type (digital camera vs. yogurt vs. wine). Both were between-subject factors. We used three different products for greater generalisability of the results. Thus, the product condition in the factorial design was not part of our research model but was included in our data analysis to ensure that the results were the same for all three products used. We chose digital cameras, yogurt and wine for three reasons:

1 the products belong to different price segments

2 differ in their domains

3 are non-essential goods.

This selection is also consistent with prior research (Jiang and Wang, 2008). All three types of products can be consulting intensive. First, digital cameras are technical products that offer a variety of different features. Here, a consumer may want to know about the quality and durability of these features, which could be obtained by product reviews (ibid.). Second, yogurt as nutrition good is also consulting sensitive for consumers, which diet, are ecology-minded individuals, have to avoid lactose or have individual nutrition allergies and therefore have to request reviews (Maes and Mistry, 2009). And finally, the selection of the right wine is important for consumers, who plan a dinner and want to know which wine fits to a given meal or want to impress their guests. 
A total of 116 subjects was recruited from a German university. This sample was composed of 83 male and 31 female students with two subjects giving no answer. Their age ranged between 18 and $19(n=4), 20$ and $24(n=71), 25$ and $29(n=37)$ and from 30 to $34(n=3)$ with one subject giving no answer. The students were interested in media design $(n=51)$, computer science $(n=37)$ and economics $(n=12)$ with 16 subjects giving no answer.

Table $1 \quad$ Study design

\begin{tabular}{lccc}
\hline & & \multicolumn{2}{c}{ Product review } \\
\cline { 3 - 4 } & & Free $($ costs $=0)$ & Fee $($ costs $>0)$ \\
\hline Product & Digital camera & Group A $(n=21)$ & Group B $(n=19)$ \\
& Yogurt & Group C $(n=21)$ & Group D $(n=18)$ \\
& Wine & Group E $(n=18)$ & Group F $(n=19)$ \\
\hline
\end{tabular}

Note: 116 subjects were randomly assigned to the six groups.

For each product and product review type, we developed separate questionnaires. First of all, each subject was shown an in-store shopping scenario on a picture. This scenario was not related to the products of this study to reduce an individual bias of the subjects when rating the product-specific items of the questionnaire. It showed product shelves with RFID-tagged mobile navigation units and a mobile device capable of identifying the products with an RFID-reader as depicted in Figure 2. Subjects were told that they own this mobile device and that they can request product reviews with it after they had touched the product in question with the RFID-reader attached to it. Then, all subjects were asked to rate their intention to use reviews for the product in question on their mobile device

1 in general (all groups)

2 when product reviews are provided by a user-community (the Amazon model) and could be accessed for free (groups A, C and E) or when product reviews are provided by experts and they had to pay for it (groups B, D and F).

Figure 2 Consumer using an RFID-enabled mobile device within a retail store selling mobile navigation units
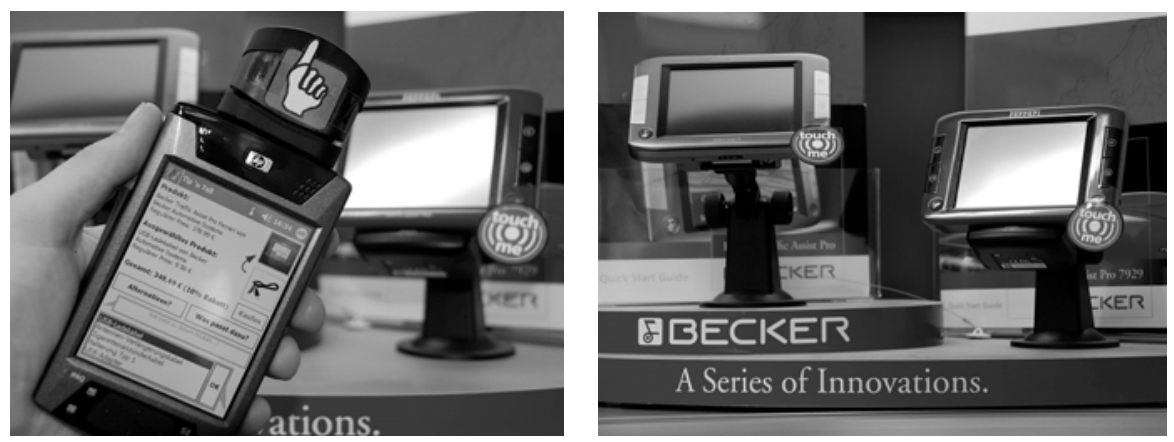
Figure 2 Consumer using an RFID-enabled mobile device within a retail store selling mobile navigation units (continued)

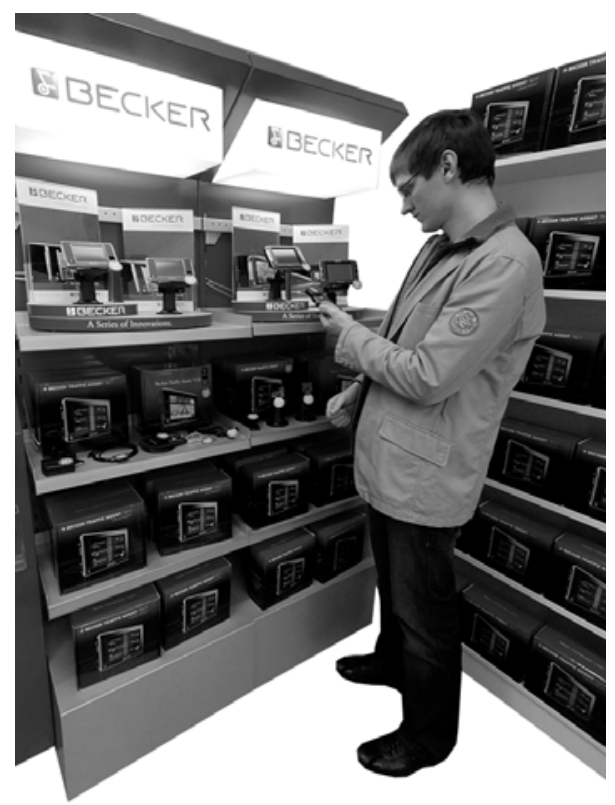

In addition, the subjects of groups B, D and F were asked how much of the product's price they were willing to pay for the review in order to provide first guidelines for pricing considerations. Here, we chose a relative approach to identify participants' willingness to pay, because the value of information is highly subjective (Raban, 2007; Raban and Rafaeli, 2006).

\subsection{Instrument}

For our survey instrument, we adapted scales from Davis (1989) based on the work of Ajzen and Fishbein (1980) for defining the behavioural intention to use digital product reviews. Accordingly, the behavioural intention covers the four behavioural elements action (usage), target (product reviews obtained from a mobile device), context (buying a product in a bricks-and-mortar store), and time (the time of the survey) when measuring the behaviour in question. Likewise, the measure intention to prefer a review-enabled retail store was adapted from Kamis et al. (2008). Consistent with prior research, all items with the exception of the maximal amount of the review's fee were based on seven-point Likert scales, ranging from extremely disagree (1) to extremely agree (7). All items are shown in Table 2.

\subsection{Data analysis and results}

We calculated several metrics to describe the results of the study. Beside the mean values and standard deviations, we used one-sample $t$-tests to evaluate the fact whether the mean value of the ratings was significantly above or below the neutral test value four on the 
seven-point Likert scales, thus indicating the strength of intentions of the subjects. For all constructs, these descriptive statistics are shown in Table 3.

Table 2 Constructs and items of the questionnaires

\begin{tabular}{|c|c|c|}
\hline & Construct & Item \\
\hline IUG & $\begin{array}{l}\text { Intention to use } \\
\text { product reviews in } \\
\text { general }\end{array}$ & $\begin{array}{l}\text { I would use digital product reviews on my mobile device at } \\
\text { the point of sale to purchase a [digital camera } \mid \text { yogurt } \mid \text { wine]. }\end{array}$ \\
\hline IUM & $\begin{array}{l}\text { Intention to use } \\
\text { product reviews } \\
\text { (free } \mid \text { fee manipulated) }\end{array}$ & $\begin{array}{l}\text { I would use digital product reviews on my mobile device at } \\
\text { the point of sale to purchase a [digital camera } \mid \text { yogurt } \mid \text { wine], } \\
\text { if they are available for [free and provided by a user } \\
\text { community | a fee and provided by professionals]. }\end{array}$ \\
\hline IPS & $\begin{array}{l}\text { Intention to prefer a } \\
\text { review-enabled store }\end{array}$ & $\begin{array}{l}\text { I would prefer a retail store for buying a } \\
\text { [digital camera } \mid \text { yogurt } \mid \text { wine] that offers me product } \\
\text { reviews on my mobile device if they are available for } \\
\text { [free and provided by a user community } \mid \text { a fee and } \\
\text { provided by professionals]. }\end{array}$ \\
\hline MAF & $\begin{array}{l}\text { Maximal amount of } \\
\text { the review's fee }\end{array}$ & $\begin{array}{l}\text { How much of the product's price would you pay for a } \\
\text { product review (in percent)? }\end{array}$ \\
\hline
\end{tabular}

Table 3 Descriptive statistics for the constructs IUG, IUM, IPS, and MAF

\begin{tabular}{lccccc}
\hline Construct (product) & Group(s) & N & Mean & SD & $\begin{array}{c}\text { One sample t-test, } \\
\text { test value }=4\end{array}$ \\
\hline IUG (digicam) & A and B & 40 & 5.51 & 1.69 & $p<.001 * * *$ \\
IUG (yogurt) & C and D & 39 & 3.79 & 1.86 & $p=.497$ \\
IUG (wine) & E and F & 37 & 4.38 & 1.95 & $p=.245$ \\
IUM (free, digital cam.) & A & 21 & 5.67 & 1.39 & $p<.001 * * *$ \\
IUM (free, yogurt) & C & 21 & 3.67 & 1.80 & $p=.406$ \\
IUM (free, wine) & E & 18 & 4.06 & 1.89 & $p=.902$ \\
IUM (fee, digital cam.) & B & 19 & 2.89 & 1.78 & $p<.017 *$ \\
IUM (fee, yogurt) & D & 18 & 1.89 & 1.45 & $p<.001 * * *$ \\
IUM (fee, wine) & F & 19 & 2.26 & 1.44 & $p<.001 * * *$ \\
IPS (free, digital cam.) & A & 21 & 4.45 & 1.19 & $p=.107$ \\
IPS (free, yogurt) & B & 19 & 3.43 & 1.66 & $p=.130$ \\
IPS (free, wine) & E & 18 & 3.89 & 2.22 & $p=.834$ \\
IPS (fee, digital cam.) & C & 21 & 2.89 & 1.75 & $p<.015 *$ \\
IPS (fee, yogurt) & D & 18 & 2.00 & 1.46 & $p<.001 * * *$ \\
IPS (fee, wine) & F & 19 & 2.37 & 1.57 & $p<.001 * * *$ \\
MAF (digital cam.) & B & 19 & $2.17 \%$ & 1.58 & N/A \\
MAF (yogurt) & D & 18 & $1.94 \%$ & 1.47 & N/A \\
MAF (wine) & F & 19 & $4.45 \%$ & 2.63 & N/A \\
MAF (all products) & B, D and F & 56 & $2.85 \%$ & 2.20 & N/A \\
\hline Nos * $<0.05, * * p$ & & & &
\end{tabular}

Notes: ${ }^{*} p<0.05,{ }^{* *} p<0.01, * * * p<0.001$ 
Results show that the subjects only intend to use product reviews in general when they are to buy digital cameras as the mean value of 5.51 (for digital cameras) lies significantly above 4 at the .001 level, whereas 3.79 (yogurt) and 4.38 (wine) do not. Consistently, the behavioural intention to use free product reviews provided by a user-community applies only for digital cameras. But if subjects have to pay for reviews that are provided by experts, they do not intend to use them for all three types of products. The latter result applies for the behavioural intention to prefer review-enabled stores, too. Thus, subjects do not prefer review-enabled stores if they have to pay for the digital cameras', yogurts' or wine's product reviews provided by professionals. The average amount of the review's fee that the subjects were willing to pay lies at $2.85 \%$ of a product's price. This amount is higher for wine (4.45) than for digital cameras $(2.17 \%)$ or yoghurts $(1.94 \%)$.

According to hypotheses $\mathrm{H} 1$ and $\mathrm{H} 2$, we used multivariate analysis of variance (MANOVA) to test whether the type of the product review, i.e., free versus paid, resulted in significant differences of responses for both constructs, the intention to use product reviews and the intention to prefer review-enabled retail stores. Given the sample sizes of the smallest cells (see Table 1) and by conducting power analysis with G*Power3 (Faul et al., 2007), we can identify large effects $\left(f^{2}=.30\right)$ with a statistical power of .80 (statistical test: $F$-test, MANOVA, Global effects, $p=.05$, total sample size $=36$, two groups, two response variables), which is common in MIS research (Cohen, 1977). The results of MANOVA are shown in Table 4.

Table 4 Multivariate analysis of variance with product type (free versus paid) being the independent variable and IUM and IPS being the dependent variables

\begin{tabular}{lcccccc}
\hline Product & Measure & H's trace & Wilk's $\lambda$ & $R^{2}$ & F-value & $p$-value \\
\hline Digital camera & Overall & .784 & .561 & - & 13.72 & $<.001^{* * *}$ \\
A (free) $\times$ B (paid) & IUM & - & - & .439 & 29.93 & $<.001^{* * *}$ \\
& IPS & - & - & .227 & 10.56 & $=.003^{* *}$ \\
Yogurt & Overall & .348 & .742 & - & 6.29 & $=.005^{* *}$ \\
C (free) $\times$ D (paid) & IUM & - & - & .234 & 11.28 & $=.002^{* *}$ \\
& IPS & - & - & .178 & 8.03 & $=.007^{* *}$ \\
Wine & Overall & .322 & .756 & - & 5.48 & $=.009^{* *}$ \\
E (free) $\times$ F (paid) & IUM & - & - & .231 & 10.54 & $=.003^{* *}$ \\
& IPS & - & - & .143 & 5.83 & $=.021 *$ \\
\hline
\end{tabular}

Notes: $* p<0.05,{ }^{* *} p<0.01, * * * p<0.001 ; \mathrm{H}$ 's trace $=$ Hotelling's trace

For both constructs and all products, we identified significant differences. In particular, the differences were highly significant at the .001 level and the highest variance was explained when looking at the intention to use product reviews construct for digital cameras. By contrast, the difference was significant at the .01 level for all the other cases except for wine reviews and the intention to prefer review-enabled stores. Regarding the latter, we only found a significant difference at the .05 level. But all in all, the first two hypotheses are supported by the empirical data.

In order to test the third hypothesis, we calculated Pearson's correlation coefficient for the relation between intention to use product reviews and the intention to prefer review-enabled stores. Again, by conducting power analysis, we were able to identify 
large effects $\left(f^{2}=.39\right)$ with a statistical power of .80 (statistical test: correlation, point biserial model, $p=.05$, total sample size $=36$ ). As shown in Table 5, all constructs correlate significantly at the .001 level for digital cameras, yogurt and wine. Therefore, also the third hypothesis is supported.

Table 5 Pearson's correlation coefficients for the constructs IUM and IPS

\begin{tabular}{lllc}
\hline Constructs & Groups & $N$ & Correlation coefficient \\
\hline IUM $\times$ IPS (digital camera) & A and B & 40 & $.69 * * *$ \\
IUM $\times$ IPS (yogurt) & C and D & 39 & $.62 * * *$ \\
IUM $\times$ IPS (wine) & E and F & 37 & $.60 * * *$ \\
\hline
\end{tabular}

Note: $* * * p<.001$

\section{Discussion}

As shown in the last section, all three hypotheses are supported by the empirical data. In the following, the results are discussed in detail from a theoretical perspective, then managerial implications are suggested and finally, limitations of the study are addressed.

\subsection{Theoretical implications}

First of all, the fee of the product review negatively influences the intention to use the review (see Table 3, rows 7-9). This is valid for all product types: digital cameras, yogurt and wine. Therefore, fees are barriers for the adoption of reviews. But one have to bear in mind that although fees reduce the intention to use reviews, free reviews provided by user-communities were only adopted significantly for digital cameras as shown in Table 3 (rows 4-6). Thus, it is suggested that the type of the product plays a major role in evaluating the adoption of product reviews and should be part of the research model, either as an independent or mediating variable. In particular, we suggest to test products that differ in terms of experience and search characteristics (Franke et al., 2004; Mudambi and Schuff, 2010), their perceived luxuriousness, quality or price (Hansen, 2005). This will lead to a better understanding of the adoption of reviews depending on particular product attributes. Additionally, the adoption of digital product reviews may also be influenced by the perceived complexity of products. Here, we assume two kinds of levels. After reaching the first level, digital product reviews are adopted when they are provided for free as we have found for digital cameras in our case. But there may also exist a higher threshold of product complexity, from which onwards consumers would pay for a digital product review when provided by an expert. But it is still an open issue, whether those complex products are available in retail stores today and thus, further investigations are needed.

Second, the fee of the product review has a negative relationship with the intention to prefer review-enabled stores. This relationship is valid for all product types, too. Thus, the fee prevents review-enabled stores to be preferred. While MANOVA resulted in stronger differences for the intention to use product reviews $(p<.001$ for digital cameras and $p<.05$ for yogurt and wine), the differences for the intention to prefer review-enabled stores is weaker $(p<.01$ for digital cameras and yogurt and $p<.05$ for wine). One reason may be the fact that for all product types the mean values of the 
intention to prefer review-enabled stores do not lie significantly above the neutral test value of 4 if product reviews are available for free (Table 3, rows 10-12); they lie only significantly below the test value for the paid review cases (Table 3, rows 13-15). Another more obvious reason may lie in other factors that have a greater influence on store preference. These factors may be the proximity between the store and the customer's location, the price-levels of the products, the customers' relationship to sales personnel (Ponder et al., 2006) or the design of the shopping environment (Bitner, 1992). Therefore, one has to consider and evaluate the relative importance of product review offerings with those factors that influence customers' preferences in selecting retail stores, too.

Third, the intention to use product reviews predicts strongly the intention to prefer review-enabled stores. This correlation applies for all product types as shown in Table 5 and thus successfully applies TRA/TPB to the adoption of product reviews. In line with this result, product reviews as a supporting service are therefore able to increase customer loyalty. Thus, reviews might be one of several factors that influences store preference and return behaviour through customer satisfaction or shopping enjoyment (Kamis et al., 2008; van Riel et al., 2004; Kabadayi and Gupta, 2005).

\subsection{Practical implications}

As managerial implication, the extension of physical products with free or paid product information services may change the way of retailing in bricks-and-mortar stores. With the help of mobile devices that bridge the gap between physical products and online services, static product information becomes interactive. This kind of interactive product information provides several benefits to the retail ecosystem. First, consumers perceive interactive product information as more useful in in-store purchase decisions compared to static information and thus, would prefer those interactive-enabled stores (Kowatsch and Maass, 2010). In addition, Ballantine and Fortin (2009) have even proven that higher levels of interactivity with product information increases purchase intentions of consumers because of higher perceptions of shopping pleasure and arousal. Although the findings of Ballantine and Fortin have been only validated in online shopping environments, they might also be valid for in-store shopping scenarios for the same reasons even though with less strong effects due to physical surroundings (Bitner, 1992). Furthermore, retailers might develop new business models that do not focus on one core actor but rather on a network of business actors (Komulainen et al., 2006). For example, they might cooperate with providers of product reviews and price their products dynamically. In this case, the price of the product might include at least one product review provided by a professional third-party organisation for free. Such a dynamic pricing scenario could even be extended with personalised pricing strategies as the value of information is highly subjective (Raban, 2007; Raban and Rafaeli, 2006). As a result, providers of online reviews would benefit from a new market, the in-store customers. By contrast, retailers would be able to provide new supporting product services to their existing customers (van Riel et al., 2004), which would have used these services otherwise at home buying the product even elsewhere at the worst case.

Concerning product review services and the results of our study, we recommend providers of product reviews to focus on the consumer electronics domain and serve reviews for free in the first instance. If a fee is inevitable, then it should range between $2 \%$ and $5 \%$ of the product's price as Table 3 indicates. Moreover, ease of use of 
applications with fast product identification technologies are enablers for those systems to be adopted (Kowatsch and Maass, 2010). Therefore, software applications with fast identification technologies need to be developed and evaluated. For instance, developers may use the camera of a mobile phone to identify products with barcodes or QR codes, e.g., by using Google's Android development kit or Apple's iPhone platform. But also radio frequency technology as used in Nokia's NFC devices may be suitable for fast product identification assuming the existence of products tagged with RFID antennas. Although there exist some of these applications such as MASSI (Metro AG), the Tip'n Tell client (Kowatsch and Maass, 2010) or the Mobile Prosumer (Resatsch et al., 2008), they have two shortcomings: they show a slow performance and the link to value added services such as product reviews is still missing. But prototypical applications are currently being developed that may overcome these shortcomings, in particular with a focus on product reviews (von Reischach and Michahelles, 2008).

Finally, we recommend store managers to provide a free wireless network infrastructure (e.g., WLAN) and products, which can be easily identified by RFID or QR codes, to their customers. This would not only enhance the retailer's competitive advantage as it may attract more customers, which would otherwise find and buy adequate products online at home, but this may also increase the customer's shopping experience in retail stores.

\subsection{Limitations}

Our study has limitations that must be pointed out as well. First, we did not measure the actual use of product reviews in a field setting but did only focus on behavioural intentions. Although there exist studies that have positively evaluated the relationship between behavioural intention and actual behaviour (e.g., Ajzen and Fishbein, 1980; Venkatesh et al., 2003b), this positive relation is not guaranteed per se. Intentions do therefore not necessarily lead to the behaviour in question, i.e., use of product reviews when provided for free. Thus, our results rather estimate actual behaviour.

Second, the sample of our study was relatively small and the participants were students, which is not representative for consumers of retail stores in general. We found therefore astonishingly clear results that are moderated by the fact that subjects were mostly technically savvy individuals. Hence, it is expected that individuals with less technical knowledge show smaller effects. Nevertheless, we want to make sure that at least technically savvy individuals adopt product reviews in purchase situations before a more representative field experiment is conducted.

A last shortcoming of our study lies in the subjects' motivation to perform the decision-making task, which was externally motivated, i.e., by our scenario, rather than intrinsically. Thus, the utility of digital product reviews may be moderated by the extent of the task motivation of the participants (Chan, 2009).

\section{Summary and future work}

In this paper, we studied the use of free and paid digital product reviews. In contrast to prior work, this paper provides new insights as the reviews are requested on mobile devices in in-store purchase situations. For this purpose, we developed a research model and tested it empirically. Results indicate that 
1 product reviews of digital cameras obtained by mobile devices are adopted in general at the point of sale

2 the adoption rate of digital product reviews is higher when they were available for free and provided by user-communities instead of experts

3 those stores were preferred which offer these reviews

4 the intention to use product reviews strongly predicts the customer's intention to prefer review-enabled stores.

Thus, digital product reviews should be designed for mobile devices, such that they can be used fast and easily in bricks-and-mortar stores. Correspondingly, store managers should offer a free communication infrastructure to increase consumer frequency through the availability of digital product reviews. Furthermore, we suggest that digital product reviews can increase perceived confidence in purchase decisions and therefore reduce purchase time and increase customer satisfaction.

Consistent with the discussion above, future work will study the impact of digital product reviews on the duration of purchase decisions to see if search effort can be reduced with regard to cognitive load theory (Bo and Benbasat, 2007; Häubl and Trifts, 2000). Accordingly, further research will address the question how reviews can be visualised adequately on small screens such as on mobile devices and at the same time reduce cognitive effort for purchase decision-making (Lee and Benbasat, 2003). In addition, product attributes such as price or quality and the distinction between search and experience goods must be considered when reviews are evaluated (Mudambi and Schuff, 2010). Furthermore, product reviews might be adopted rather for high-complex and high-involvement products such as cars than for low-complex and low-involvement products such as coffee (Radder and Huang, 2008). Then, investigations should be made into the relative importance of product reviews compared to contextual factors (Dabholkar and Bagozzi, 2002) that also influence a consumer's product choice such as waiting time, social anxiety or personal relationships between buyers and sellers. Shopping situations that are motivated rather intrinsically (e.g., buying a product for own purposes) than extrinsically (e.g., buying a product on request of another person) may moderate adoption behaviour of product reviews as well. Finally, perceived trust in the review provider may also play a major role in the adoption of digital product reviews under trust and relevance considerations (Komiak and Benbasat, 2006) and thus needs further investigation, too.

\section{Acknowledgements}

This work was partially funded by the German Federal Ministry for Education and Research (BMBF) under the contract 1753X07. This work was also co-funded by the European Union under the contract ICT-231527. The authors would like to thank Sabine Janzen, Andreas Filler, Daphne Raban and the reviewers for their valuable feedback that helped improve this paper originally published at the 4th Mediterranean Conference on Information Systems (MCIS 2009) in Athens, Greece. 
The role of product reviews on mobile devices for in-store purchases

\section{References}

Ajzen, I. (1991) 'The theory of planned behavior', Organizational Behavior and Human Decision Processes, Vol. 50, pp.179-211.

Ajzen, I. and Fishbein, M. (1980) Understanding Attitudes and Predicting Social Behaviour, Prentice Hall, Inglewood Cliffs, NJ.

Ballantine, P.W. and Fortin, D.R. (2009) 'The effects of interactivity and product information on consumers' emotional responses to an online retail setting', International Journal of Internet Marketing and Advertising, Vol. 5, No. 4, pp.260-271.

Bettman, J.R., Luce, M.F. and Payne, J. (1998) 'Constructive consumer choice processes', Journal of Consumer Research, Vol. 25, No. 3, pp.187-217.

Bitner, M.J. (1992) 'Servicescapes: the impact of physical surroundings on customers and employees', Journal of Marketing, Vol. 56, No. 2, pp.57-71.

Bo, X. and Benbasat, I. (2007) 'E-commerce product recommendation agents: use, characteristics, and impact', MIS Quarterly, Vol. 31, No. 1, pp.137-209.

Chan, S.H. (2009) 'The roles of user motivation to perform a task and decision support system (DSS) effectiveness and efficiency in DSS use', Computers in Human Behavior, Vol. 25, No. 1, pp.217-228.

Chen, P.Y., Wu, S.Y. and Yoon, J. (2004) 'The impact of online recommendations and consumer feedback on sales', Proceedings of the 25th International Conference on Information Systems (ICIS 2004), Washington, D.C., USA.

Chen, Y. and Xie, J. (2005) 'Third-party product review and firm marketing strategy', Marketing Science, Vol. 24, No. 2, pp.218-240.

Cohen, J. (1977) Statistical Power Analysis for the Behavioral Sciences, Academic Press, New York, USA.

Dabholkar, P.A. and Bagozzi, R.P. (2002) 'An attitudinal model of technology-based self-service: moderating effects of consumer traits and situational factors', Journal of the Academy of Marketing Science, Vol. 30, No. 3, pp.185-201.

Davis, F.D. (1989) 'Perceived usefulness, perceived ease of use, and user acceptance of information technology', MIS Quarterly, Vol. 13, No. 3, pp.319-339.

DoubleClick (2004) 'DoubleClick's touchpoints II: the changing purchase process', March, available at http://class.classmatandread.net/dct/dc_touchpoints_0403.pdf.

Faul, F., Erdfelder, E., Lang, A.G. and Buchner, A. (2007) 'G*Power3: a flexible statistical power analysis program for the social, behavioral, and biomedical sciences', Behavior Research Methods, Vol. 39, No. 2, pp.175-191.

Franke, G., Huhmann, B. and Mothersbaugh, D. (2004) 'Information content and consumer readership of print ads: a comparison of search and experience products', Journal of the Academy of Marketing Science, Vol. 32, No. 1, pp.20-31.

Hansen, T. (2005) 'Perspectives on consumer decision making: an integrated approach', Journal of Consumer Behaviour, Vol. 4, No. 6, pp.420-437.

Häubl, G. and Trifts, V. (2000) 'Consumer decision making in online shopping environments: the effects of interactive decision aids', Marketing Science, Vol. 19, No. 1, pp.4-21.

Hevner, A.R., March, S.T., Park, J. and Ram, S. (2004) 'Design science in information systems research', MIS Quarterly, Vol. 28, No. 1, pp.75-105.

Jiang, B-J. and Wang, B. (2008) 'Impact of consumer reviews and ratings on sales, prices, and profits: theory and evidence', Proceedings of the 29th International Conference on Information Systems (ICIS), Paris, France.

Kabadayi, S. and Gupta, R. (2005) 'Website loyalty: an empirical investigation of its antecedents', International Journal of Internet Marketing and Advertising, Vol. 2, No. 4, pp.321-345. 
Kamis, A., Koufaris, M. and Stern, T. (2008) 'Using an attribute-based decision support system for user-customized products online: an experimental investigation', MIS Quarterly, Vol. 32, No. 1, pp.159-177.

Kim, H-W., Chan, H.C. and Gupta, S. (2007) 'Value-based adoption of mobile internet: an empirical investigation', Decision Support Systems, Vol. 34, No. 1, pp.111-126.

Komiak, S.Y.X. and Benbasat, I. (2006) 'The effects of personalization and familiarity on trust and adoption of recommendation agents', MIS Quarterly, Vol. 30, No. 4, pp.941-960.

Komulainen, H., Mainela, T., Sinisalo, J., Tahtinen, J. and Ulkuniemi, P. (2006) 'Business model scenarios in mobile advertising', International Journal of Internet Marketing and Advertising, Vol. 3, No. 3, pp.254-270.

Konana, P. and Ray, G. (2007) 'Physical product reengineering with embedded information technology', Communications of the ACM, Vol. 50, No. 10, pp.72-78.

Kowatsch, T. and Maass, W. (2010) 'In-store consumer behavior: how mobile recommendation agents influence usage intentions, product purchases, and store preferences', Computers in Human Behavior, Vol. 26, No. 4, pp.697-704.

La, K.V., Walker, R. and Kam, B. (2005) 'Customer loyalty in e-retailing: an exploratory study', International Journal of Internet Marketing and Advertising, Vol. 2, No. 3, pp.237-258.

Lee, Y.E. and Benbasat, I. (2003) 'Interface design for mobile commerce', Communications of the $A C M$, Vol. 46, No. 12, pp.48-52.

Li, X. and Hitt, L.M. (2008) 'Self-selection and information role of online product reviews', Information Systems Research, Vol. 19, No. 4, pp.456-474.

Maass, W. and Varshney, U. (2008) 'Preface to the focus theme section: 'smart products", Electronic Markets, Vol. 18, No. 3, pp.211-215.

Maass, W., Filler, A. and Janzen, S. (2008) 'Reasoning on smart products in consumer good domains', in Mühlhäuser, M., Ferscha, A. and Aitenbichler, E. (Eds.): Constructing Ambient Intelligence, pp.165-173, Springer, Berlin.

Maes, P. and Mistry, P. (2009) 'Unveiling the 'sixth sense': game-changing wearable tech', March, available at http://www.ted.com/talks/pattie maes demos the sixth sense.html.

Moon, B-J. (2004) 'Consumer adoption of the internet as an information search and product purchase channel: some research hypotheses', International Journal of Internet Marketing and Advertising, Vol. 1, No. 1, pp.104-118.

Moore, G.C. and Benbasat, I. (1991) 'Development of an instrument to measure the perceptions of adopting an information technology innovation', Information Systems Research, Vol. 2, pp.173-191.

Mudambi, S.M. and Schuff, D. (2010) 'What makes a helpful online review? A study of customer reviews on Amazon.com', MIS Quarterly, Vol. 34, No. 1, pp.185-200.

Piller, C. (1999) 'Everyone is a critic in cyberspace', Los Angeles Times, 3 December.

Ponder, N., Lueg, J.E. and Williams, Z. (2006) 'Salesperson assistance versus self-service in retailing: are they both a matter of convenience?', Marketing Management Journal, Vol. 16, No. 1, pp.72-87.

Raban, D.R. (2007) 'User-centered evaluation of information: a research challenge', Internet Research, Vol. 17, No. 3, pp.306-322.

Raban, D.R. and Rafaeli, S. (2006) 'The effect of source nature and status on the subjective value of information', Journal of the American Society for Information Science and Technology, Vol. 57, No. 3, pp.321-329.

Radder, L. and Huang, W. (2008) 'High-involvement and low-involvement products: a comparison of brand awareness among students at a South African university', Journal of Fashion Marketing and Management, Vol. 12, No. 2, pp.232-243.

Resatsch, F., Sandner, U., Leimeister, J.M. and Krcmar, H. (2008) 'Do point of sale RFID-based information services make a difference? Analyzing consumer perceptions for designing smart product information services in retail business', Electronic Markets, Vol. 18, No. 3, p.216. 
Rogers, E.M. (2003) Diffusion of Innovations, Free Press, New York.

Shapiro, C. and Varian, H.R. (1999) Information Rules - A Strategic Guide to the Network Economy, Harvard Business School Press, Watertown MA.

Stahl, F. and Maass, W. (2006) 'Adoption and diffusion in electronic markets: an empirical analysis of attributes influencing the adoption of paid content', Electronic Markets, Vol. 16, No. 3, pp.233-244.

van Riel, A.C.R., Lemmink, J., Streukens, S. and Liljander, V. (2004) 'Boost customer loyalty with online support: the case of mobile telecoms providers', International Journal of Internet Marketing and Advertising, Vol. 1, No. 1, pp.4-23.

Venkatesh, V., Morris, M.G., Davis, G.B. and Davis, F.D. (2003a) 'User acceptance of information technology: toward a unified view', MIS Quarterly, Vol. 27, No. 3, pp.425-478.

Venkatesh, V., Ramesh, V. and Massey, A.P. (2003b) 'Understanding usability in mobile commerce', Communications of the ACM, Vol. 46, No. 12, pp.53-56.

von Reischach, F. and Michahelles, F. (2008) 'APriori: a ubiquitous product rating system', Proceedings of the Workshop on Pervasive Mobile Interaction Devices (PERMID) at Pervasive 2008, Sydney, Australia.

Wang, A. (2008) 'Consensus and disagreement between online peer and expert recommendations', International Journal of Internet Marketing and Advertising, Vol. 4, No. 4, pp.328-349. 